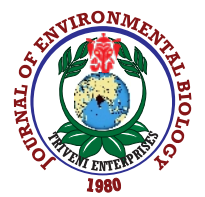

\title{
Variability and genetic diversity study based on agro- morphological traits in a diverse set of Indian mustard [Brassica juncea (L.) Czern. \& Coss.] germplasm
}

\author{
H.K. Sharma*, A. Kumar, V.V. Singh, H.S. Meena, Priyamedha, P. Sharma and P.K. Rai \\ ICAR-Directorate of Rapeseed-Mustard Research, Bharatpur-321 303, India \\ *Corresponding Author Email : harrygpb@gmail.com
}

\section{Abstract}

Aim: The present investigation was designed to evaluate 150 diverse germplasm of Indian mustard along with five checks for seed yield and attributing traits.

Methodology: A total of 150 genotypes of Indian mustard were evaluated in Augmented Block Design along with five check cultivars (Kranti, Maya, Pusa Bold, NPJ-112, RGN 73) in five blocks. Data were collected for 16 different quantitative traits on each genotype.

Results: ANOVA revealed significant differences between genotypes for all traits studied. Seed yield plant $^{-1}$ had significant and positive correlation with most of the yield contributing traits. For seed yield/plant, 15 accessions (DRMR1722, BDJ-I-538, DRMR-4, JMG-113, DRMR-681, DRMR-1849, DRMR-1697, DRMR-1610, DRMR-1996, DRMR-107, DRMR-1588, DRMR-1379, DRMR-1995, IB-26, DRMR-2116) were significantly superior over best check.
Evaluation of 150 genotypes of Indian mustard in ABD along with 5 checks

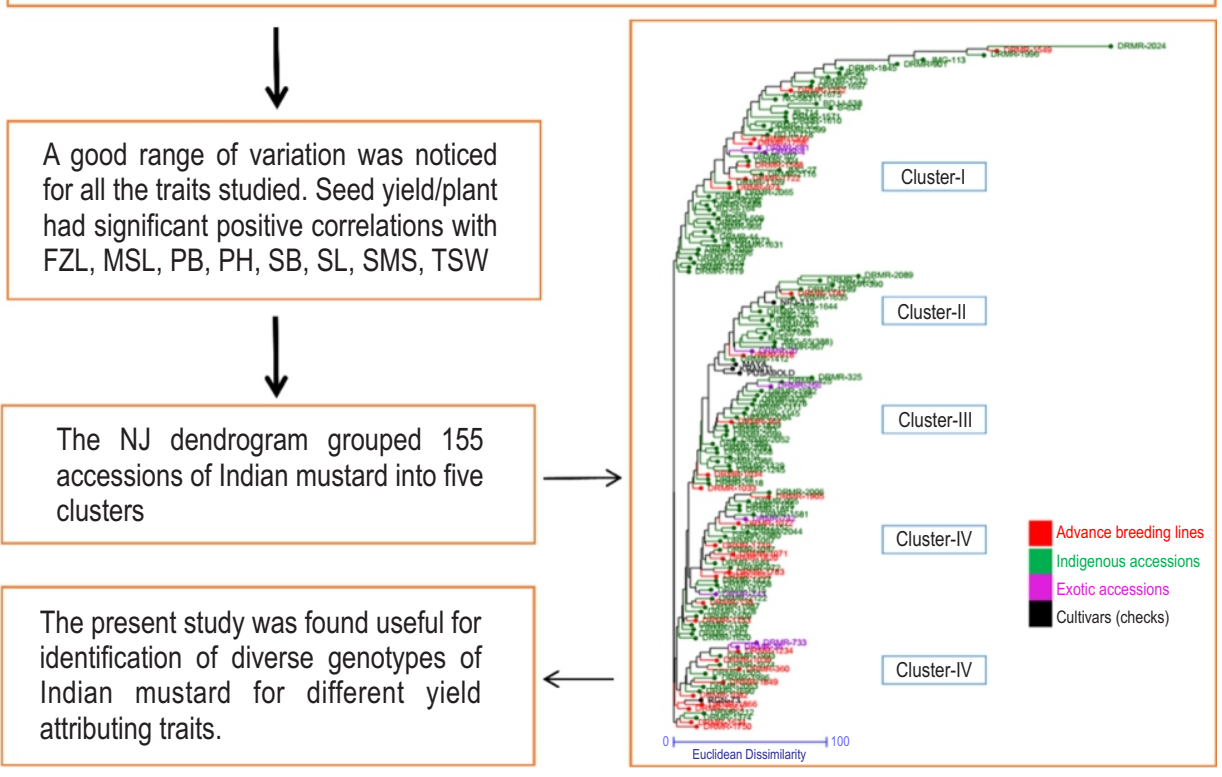

The NJ dendrogram grouped 155 accessions of Indian mustard into five clusters

The present study was found useful for identification of diverse genotypes of Indian mustard for different yield attributing traits.

Interpretation: The present study was found useful for identification of diverse genotypes of Indian mustard for different yield attributing traits. The promising lines will be utilized in Indian mustard breeding for improving seed yield and oil content.

Key words: Brassicajuncea, Correlation, Genetic diversity, Indian mustard, Variability

How to cite : Sharma, H.K., A. Kumar, V.V. Singh, H.S. Meena, Priyamedha, P. Sharma and P.K. Rai: Variability and genetic diversity study based on agromorphological traits in a diverse set of Indian mustard [Brassica juncea (L.) Czern. \& Coss.] germplasm. J. Environ. Biol., 42, 1495-1504 (2021). 


\section{Introduction}

The family Brassicaceae comprises 338 genera and 3709 species (Warwick et al., 2006) including economically important crops, weeds and ornamental plants with aesthetic values (Love et al., 2005). The genus Brassica include crop Brassicas which are major source of edible oil, vegetables and condiments. Diploid and allotetraploid species of $U$ triangle are termed as crop Brassicas. Among crop Brassicas, Brassica napus $\mathrm{L}$. and Brassica rapa $\mathrm{L}$. are categorized as rapeseed and these are cultivated mainly for the production of canola oil, while Brassica juncea (L.) Czern. \& Coss., B. carinata Braun and B. nigra (L.) Koch are placed in the mustard group and play a major role in the production of mustard oil and commercial spices (Labana and Gupta, 1993; Singh et al., 2012; Singh et al., 2018). $B$. oleracea $L$., is used as vegetable and fodder crops, under the common names of cabbage, cauliflower, broccoli, Brussels-sprout and others (Balkaya et al., 2005). Indian mustard (Brassica juncea; $2 n=36, A A B B$ ) is a self-compatible and largely a self-pollinated crop $(85-90 \%)$. It contributes more than $80 \%$ to the total rapeseedmustard production in the country and is an important component in the oilseed sector (Rambhajan et al., 1991; Shekhawat et al., 2014). Rapeseed-mustard is traditionally grown as a pure crop as well as an intercrop (mixed crop) in marginal and sub-marginal soils in the eastern, northern and north-western states of India. Among these states Rajasthan, Uttar Pradesh, Madhya Pradesh, Haryana, Gujarat are major producer of mustard crop. It requires cool and moist climate during winter season for better growth and productivity (Rathi etal., 2015; Priyanka etal., 2020).

Rapeseed-mustard accounts for nearly one-third of the oil produced in India, making it country's key edible oilseed crop. Among the seven major oilseeds grown in India, rapeseedmustard shares $28.6 \%$ in the total production of oilseeds (Priyanka et al., 2020). During 2019-20, Rapeseed-mustard was sown across 5.52 million hectare area(Second advance estimates, Agricultural Situation in India, 2020) and production was 9.116 million tones (Fourth advance estimates; https://eands.dacnet.nic.in/Advance_Estimates.htm). Rajasthan is one of the major mustard producing states in the country, contributing $40.87 \%$ of total production of India (Agricultural Statistics at a glance, 2018). Despite being the third largest producer $(11.3 \%)$ of oilseed brassica after Canada and China in the world, India meets $57 \%$ of the domestic edible oil requirement through imports (Jat et al., 2019). Hence, there is a need to enhance the edible oil production of the country to meet the domestic demand to reduce our spent on oil import.

In modern plant breeding practice, use of limited germplasm as parents coupled with intensive unidirectional selection for yield over an extended period have critically reduced the genetic diversity in many cultivated crop plants that has led to enhanced susceptibility against diseases, insect pests and climatic vagaries. Chauhan et al. (2011) reviewed the Indian mustard cultivars based on their pedigree and reported that 46 of modern Indian mustard cultivars having Varuna variety as one of the parents directly or indirectly. Chatterjee et al. (2016) reported that only limited amount of genetic diversity was transferred in to $B$. napus from its diploid progenitors and further intensive breeding eroded the variations for many traits. Hence, there is a need to incorporate fresh set of diverse lines in mustard breeding programme. Study of variability and genetic diversity can help to understand the structure of germplasm, predict which combinations would produce the best offsprings (Hu et al., 2007), and facilitate to widen the genetic base of breeding material for selection (Qi et al., 2008). Genetic diversity among germplasm lines or populations can be determined using morphological, biochemical and molecular approaches (Mohammadi and Prasanna, 2003). Variability and genetic diversity study in $B$. juncea using agro-morphological traits has previously been done by some researchers but with limited and less diverse genotypes (mostly using either limited varieties and germplasm of indigenous origin (Shekhawat et al., 2014; Gupta et al., 2018; Kumari et al., 2019; Gadi et al., 2020). Therefore, the present investigation was designed to study variability and genetic diversity in a diverse set of 150 germplasm (including indigenous landrace, advance breeding lines, varieties and exotic lines) of Indian mustard for seed yield and attributing traits and to identify promising accessions.

\section{Materials and Methods}

The experiment was conducted at research farm of ICARDirectorate of Rapeseed-Mustard Research during Rabi, 201718. ICAR-DRMR is located at $77^{\circ} 3^{\prime} \mathrm{E}$ longitude, $27^{\circ} 15^{\prime} \mathrm{N}$ latitude and at an altitude of 178.37 meter above mean sea level. The region falls under Agro climatic Zone III (semi-arid Eastern plain) with sub-tropical and semi-arid climate. A total of 150 genotypes of diverse origin including Indigenous accessions (112), exotic accessions (08) and advanced breeding lines (30) of Indian mustard were evaluated in Augmented Block Design along with 5 checks [Kranti, Maya, Pusa Bold, Pusa Mustard 25 (NPJ-112), RGN 73]. Genotypes were grown in five blocks. Single row of $3 \mathrm{~m}$ length was planted for each genotype. Five checks were replicated in five blocks. Single row of each genotype was considered as a plot. Row to row spacing was $45 \mathrm{~cm}$ and plant to plant spacing within a row was maintained at $10-15 \mathrm{~cm}$ by thinning of plants at 15-20 DAS. All recommended agronomic and plant protection measures were followed to grow a healthy, disease and pest free crop. List of genotypes and their origin are presented in Table 1 and features of check varieties is presented in Table 2.

Data were collected on five randomly selected plants for 16 different quantitative traits[IF: Days to initial flowering; F50: Days to $50 \%$ flowering; PB: No. of primary branches/plant; SB: No. of secondary branches/plant; FBB: First basal branching (cm); PH: Plan height (cm); FZL: Fruiting zone length (cm); SMS: Siliqua on main shoot (No.); MSL: Main shoot length (cm); SPY: Seed yield/plant (g); SPW: Dry weight/plant(g); DM: Days to physiological maturity; SL: Siliqua length (cm); SPS: No. of seeds/siliqua; TSW: 1000-seed weight (g); OC: Oil content (\%)] on individual genotypes. All morphological data were collected in standard units as per DUS guidelines of Indian mustard as developed by 
PPV \& FRA (PPVFRA, 2009). Oil content in seeds was estimated by Fourier transform near-infrared (FT-NIR) Spectroscopy. Mean data of five plants were used for statistical analysis. Analysis of variance (ANOVA) for different agro-morphological traits was carried out in Augmented Block Design by using online software at SSCNARS website of ICAR (https://sscnars.icar.gov.in/). Descriptive statistics estimation and Principal component analysis was done using PAST 3.0 software (Hammer et al., 2001), character association between different traits was estimated based on Pearson's correlation coefficient using SPSS 16.0 software (SPSS, 2007). Euclidean genetic distance between different genotypes were calculated using mean data of different agro-morphological traits which was further used to construct Neighbor-joining (NJ) dendrogram using DAR win 6.0 software (Perrier etal., 2006).

\section{Results and Discussion}

Variability and correlation: 150 genotypes of Indian mustard were evaluated in Augmented Block Design along with 5 checks (Kranti, Maya, Pusa Bold, NPJ-112, RGN 73). ANOVA revealed significant differences between genotypes for all traits studied. Descriptive statistics of the Indian mustard genotypes is presented in Table 3. A good range for different traits was

Table 1: List of genotypes used in the present study

\begin{tabular}{|c|c|c|c|}
\hline Groups & Origin/Source & Genotypes & No. \\
\hline $\begin{array}{l}\text { Indigenous } \\
\text { accessions }\end{array}$ & $\begin{array}{l}\text { Assam, Nagaland, Bihar, } \\
\text { Jharkhand, Delhi, Punjab, } \\
\text { Himachal Pradesh, } \\
\text { Uttar Pradesh, } \\
\text { Madhya Pradesh, } \\
\text { Andhra Pradesh, } \\
\text { Karnataka }\end{array}$ & $\begin{array}{l}\text { DRMR-425,DRMR-473,DRMR-2044,DRMR-1620,DRMR-2065,DRMR-2006, } \\
\text { DRMR-390,DRMR-2058,DRMR-2052,DRMR-2055,DRMR-2063,DRMR-1995, } \\
\text { DRMR-995,DRMR-1996,DRMR-107,DRMR-1245,DRMR-1327,DRMR-1374, } \\
\text { DRMR-1322,DRMR-1311,DRMR-2084,DRMR-1343,DRMR-1346,DRMR-1571, } \\
\text { DRMR-2089,DRMR-1635, DRMR-1509,DRMR-1581,DRMR-1242, DRMR-1372, } \\
\text { DRMR-1379,DRMR-1993,DRMR-1505,DRMR-1599,DRMR-64,DRMR-1145, } \\
\text { DRMR-1215,DRMR-1412,DRMR-1429,DRMR-1458,DRMR-1596, } \\
\text { DRMR-1389,DRMR-2024,DRMR-1109,DRMR-1427,DRMR-1105,DRMR-1829, } \\
\text { DRMR-2119,DRMR-1644,DRMR-2093,DRMR-2099,DRMR-1631,DRMR-1697, } \\
\text { DRMR-2097,DRMR-2102,DRMR-2122,DRMR-2116,DRMR-2152,DRMR-325, } \\
\text { DRMR-981,DRMR-1002,DRMR-1489,DRMR-212,DRMR-1615,DRMR-1978, } \\
\text { DRMR-1982,DRMR-293,DRMR-929,DRMR-972,DRMR-1073,DRMR-1619, } \\
\text { DRMR-1674,DRMR-1684,DRMR-1690,DRMR-1428,DRMR-44,DRMR-1610, } \\
\text { DRMR-304,DRMR-901,DRMR-1487,DRMR-1618,DRMR-1688,DRMR-1987, } \\
\text { DRMR-966,DRMR-967,DRMR-1067,DRMR-1617,DRMR-1675,DRMR-1845, } \\
\text { DRMR-1847,DRMR-1980,DRMR-1986,IB-452,IB-299,B-154,NC-57688,JMG-55 (388), } \\
\text { JMG-12,NC-58311,B-56,BDJ-I-164,BDJ-I-778,B-634,BDJ-I-538,IB-714, } \\
\text { NC-58396,IB-26,JMG-113, JMG-29, JMG-27,JMG-51,BDJ-I-509 }\end{array}$ & 112 \\
\hline $\begin{array}{l}\text { Exotic } \\
\text { accessions }\end{array}$ & Canada, Sweden, UK & DRMR-20, DRMR-4,DRMR-36,DRMR-733,DRMR-742,DRMR-743,DRMR-266, DRMR-681 & 08 \\
\hline $\begin{array}{l}\text { Advanced } \\
\text { breeding lines }\end{array}$ & $\begin{array}{l}\text { Developed through } \\
\text { breeding methods }\end{array}$ & $\begin{array}{l}\text { DRMR-1033,DRMR-1787,DRMR-1722,DRMR-1039,DRMR-1071,DRMR-1072, } \\
\text { DRMR-1082,DRMR-1252,DRMR-1309,DRMR-1549,DRMR-1553,DRMR-1634, } \\
\text { DRMR-1749,DRMR-1750,DRMR-1753, DRMR-1820,DRMR-1866,DRMR-360, } \\
\text { DRMR-1234,DRMR-1554,DRMR-1034,DRMR-1783,DRMR-1849,DRMR-1905, } \\
\text { DRMR-138,DRMR-1588,DRMR-1758,DRMR-364,DRMR-974,DRMR-918 }\end{array}$ & 30 \\
\hline
\end{tabular}

Table 2: Features of check varieties

\begin{tabular}{|c|c|c|c|}
\hline Varieties & Pedigree & Ecology & Suitable regions \\
\hline Kranti & $\begin{array}{l}\text { Selection } \\
\text { from Varuna }\end{array}$ & $\begin{array}{l}\text { Wider adaptability, Timely } \\
\text { sown irrigated conditions }\end{array}$ & $\begin{array}{l}\text { Zone-II, III, V (Delhi, Haryana, Punjab, JK, Rajasthan, } \\
\text { Uttar Pradesh, Madhya Pradesh,Bihar, Odisha, West Bengal) }\end{array}$ \\
\hline Maya & Varuna x KRV 11 & $\begin{array}{l}\text { Suitable for timely sown } \\
\text { irrigated conditions }\end{array}$ & $\begin{array}{l}\text { Zone-III (Uttar Pradesh, Uttarakhand, Madhya } \\
\text { Pradesh and parts of Rajasthan) }\end{array}$ \\
\hline Pusa Bold & Varuna x BIC 1780 & $\begin{array}{l}\text { Suitable for rainfed areas, early } \\
\text { as well as late sown, bold seeded }\end{array}$ & Zone-V (Delhi, Uttar Pradesh, east India) \\
\hline NPJ-112 & $\begin{array}{l}\text { SEJ8 } \times \text { Pusa } \\
\text { Jagannath }\end{array}$ & $\begin{array}{l}\text { Suitable for early sown irrigated } \\
\text { conditions }\end{array}$ & $\begin{array}{l}\text { Zone-II (Delhi, Haryana ,Punjab, J\&K, Rajasthan, } \\
\text { Western Uttar Pradesh) }\end{array}$ \\
\hline RGN 73 & RGN 8 x Pusa Bold & $\begin{array}{l}\text { Suitable for timely sown } \\
\text { irrigated conditions }\end{array}$ & $\begin{array}{l}\text { Zone-III (Uttar Pradesh, Uttarakhand, Madhya Pradesh } \\
\text { and parts of Rajasthan) }\end{array}$ \\
\hline
\end{tabular}




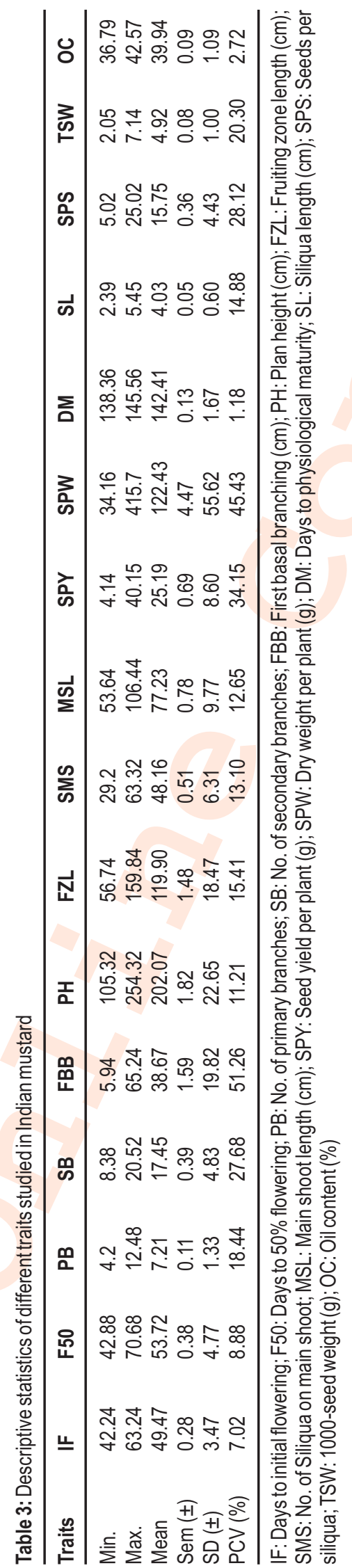


Table 4: Correlation coefficient ( $r$ ) between different quantitative traits in Indian mustard

\begin{tabular}{|c|c|c|c|c|c|c|c|c|c|c|c|c|}
\hline Trait & F50 & FBB & FZL & MSL & PB & $\mathrm{PH}$ & SB & SL & SMS & SPS & SPW & SPY \\
\hline FBB & $0.418^{* *}$ & & & & & & & & & & & \\
\hline FZL & $0.372^{* *}$ & $0.624^{* *}$ & & & & & & & & & & \\
\hline IF & $0.920^{* *}$ & $0.358^{* *}$ & $0.318^{* *}$ & & & & & & & & & \\
\hline MSL & $0.206^{\star *}$ & 0.047 & $0.361^{* *}$ & & & & & & & & & \\
\hline PB & 0.078 & $-0.312^{\star *}$ & $0.201^{*}$ & $0.199^{*}$ & & & & & & & & \\
\hline $\mathrm{PH}$ & $0.376^{* *}$ & $0.458^{* *}$ & $0.843^{* *}$ & $0.532^{* *}$ & $0.359^{* *}$ & & & & & & & \\
\hline SB & -0.029 & $-0.508^{\star *}$ & 0.054 & $0.252^{* *}$ & $0.813^{\star *}$ & $0.169^{*}$ & & & & & & \\
\hline SMS & $0.227^{\star *}$ & $0.162^{*}$ & $0.331^{* *}$ & $0.548^{* *}$ & $0.180^{*}$ & $0.429^{* *}$ & $0.174^{*}$ & 0.016 & & & & \\
\hline SPS & 0.045 & $0.170^{*}$ & -0.004 & -0.061 & $-0.349^{\star *}$ & -0.084 & $-0.398^{* *}$ & 0.145 & -0.029 & & & \\
\hline SPW & -0.072 & $-0.419^{* *}$ & 0.100 & $0.400^{* *}$ & $0.675^{\star *}$ & $0.315^{\star *}$ & $0.748^{* *}$ & 0.041 & $0.261^{* *}$ & $-0.311^{* *}$ & & \\
\hline SPY & 0.115 & -0.088 & $0.192^{*}$ & $0.351^{* *}$ & $0.376^{* *}$ & $0.326^{* *}$ & $0.451^{* *}$ & $0.191^{*}$ & $0.269^{* *}$ & -0.010 & $0.543^{* *}$ & \\
\hline TSW & $-0.260^{\star *}$ & -0.078 & 0.048 & $0.218^{* *}$ & -0.007 & 0.046 & 0.019 & $0.349^{* *}$ & 0.004 & 0.075 & $0.211^{* *}$ & $0.330^{* *}$ \\
\hline
\end{tabular}

${ }^{* *} p<0.01 ;{ }^{*} p<0.05$; Only significant correlations are presented; Trait coding is as per Table 3

Table 5: Eigen vectors and variance of first five Principal Components (PC) in Indian mustard

\begin{tabular}{llllll}
\hline Component & PC 1 & PC 2 & PC 3 & PC 4 & PC 5 \\
\hline Eigenvalue & 3281.28 & 978.043 & 123.499 & 76.602 & 48.967 \\
\% Variance & 70.797 & 21.10 & 2.66 & 1.65 & 1.06 \\
Cummulative variance & 70.79 & 91.89 & 94.56 & 96.21 & 97.27 \\
\hline
\end{tabular}

Table 6: Promising genotypes of Indian mustard identified as significantly superior over best check

\begin{tabular}{|c|c|c|c|}
\hline Traits & $\begin{array}{l}\text { Best check and } \\
\text { performance }\end{array}$ & $\begin{array}{l}\angle S D \\
(5 \%)\end{array}$ & Significantly Superior lines ( $\mathrm{N}=$ total lines) \\
\hline $\mathrm{PH}(<155 \mathrm{~cm})$ & NPJ-112 (171.2 cm) & 15.7 & DRMR-2089, DRMR-390, DRMR-1322, DRMR-1489, DRMR-1787, DRMR-1644 (N=06) \\
\hline MSL $(>89 \mathrm{~cm})$ & Kranti $(77.6 \mathrm{~cm})$ & 11.05 & $\begin{array}{l}\text { DRMR-967, DRMR-2055, DRMR-1073, DRMR-742, DRMR-64, DRMR-974, JMG-113, } \\
\text { DRMR-1428, DRMR-1374, DRMR-1505, DRMR-20, DRMR-1588, DRMR-2052, DRMR- } \\
1487 \text { (N=14) }\end{array}$ \\
\hline SMS (>55 no.) & Kranti (47.68 no.) & 06.86 & $\begin{array}{l}\text { DRMR-1599, DRMR-1631, DRMR-901, DRMR-733, DRMR-4, DRMR-1245, DRMR-36, } \\
\text { DRMR-360, BDJ-I-538, DRMR-929, DRMR-1987, DRMR-1234, JMG-113, DRMR-2063, } \\
\text { DRMR-1783, DRMR-1610, DRMR-1615, DRMR-1675, DRMR-2065, DRMR-743, DRMR- } \\
1722 \text { (N=21) }\end{array}$ \\
\hline $\mathrm{SL}(>5 \mathrm{~cm})$ & Maya $(4.1 \mathrm{~cm})$ & 0.99 & DRMR-1072, DRMR-1829, DRMR-974, DRMR-1596 (N=04) \\
\hline SPS(>23no.) & RGN-73 (18.25 no.) & 04.36 & $\begin{array}{l}\text { DRMR-1849, DRMR-1620, DRMR-2065, DRMR-473, DRMR-1039, DRMR-1619, } \\
\text { DRMR-364, DRMR-1458, DRMR-304 (N=09) }\end{array}$ \\
\hline TSW (>6.5g) & Pusa Bold (5.02 g) & 01.36 & $\begin{array}{l}\text { DRMR-1458, DRMR-1995, DRMR-2024, JMG-27, DRMR-1610, IB-26, DRMR-2065, } \\
\text { JMG-113, DRMR-1252, BDJ-I-164, DRMR-1427, DRMR-1588, DRMR-1596, } \\
\text { DRMR-2055 ( } \mathrm{N}=14 \text { ) }\end{array}$ \\
\hline FZL (>138 cm) & RGN-73 (112.6 cm) & 25.52 & $\begin{array}{l}\text { DRMR-733, BDJ-I-538, DRMR-36, DRMR-1581, DRMR-1234, DRMR-742, DRMR-1849, } \\
\text { DRMR-360, DRMR-1674, DRMR-1505, B-634, DRMR-1571, DRMR-1847, DRMR-995, } \\
\text { DRMR-1039, DRMR-1993, DRMR-1995, DRMR-2063, DRMR-1634, DRMR-1596 (N=20) }\end{array}$ \\
\hline SPY $(>37 g)$ & Pusa Bold (30.88 g) & 06.24 & $\begin{array}{l}\text { DRMR-1722, BDJ-I-538, DRMR-4, JMG-113, DRMR-681, DRMR-1849, DRMR-1697, } \\
\text { DRMR-1610, DRMR-1996, DRMR-107, DRMR-1588, DRMR-1379, DRMR-1995, IB-26, } \\
\text { DRMR-2116 (N=15) }\end{array}$ \\
\hline OC (>42 \%) & RGN-73 (41.07\%) & 01.29 & DRMR-1684 (N=01) \\
\hline
\end{tabular}

Trait coding is as per Table 3 


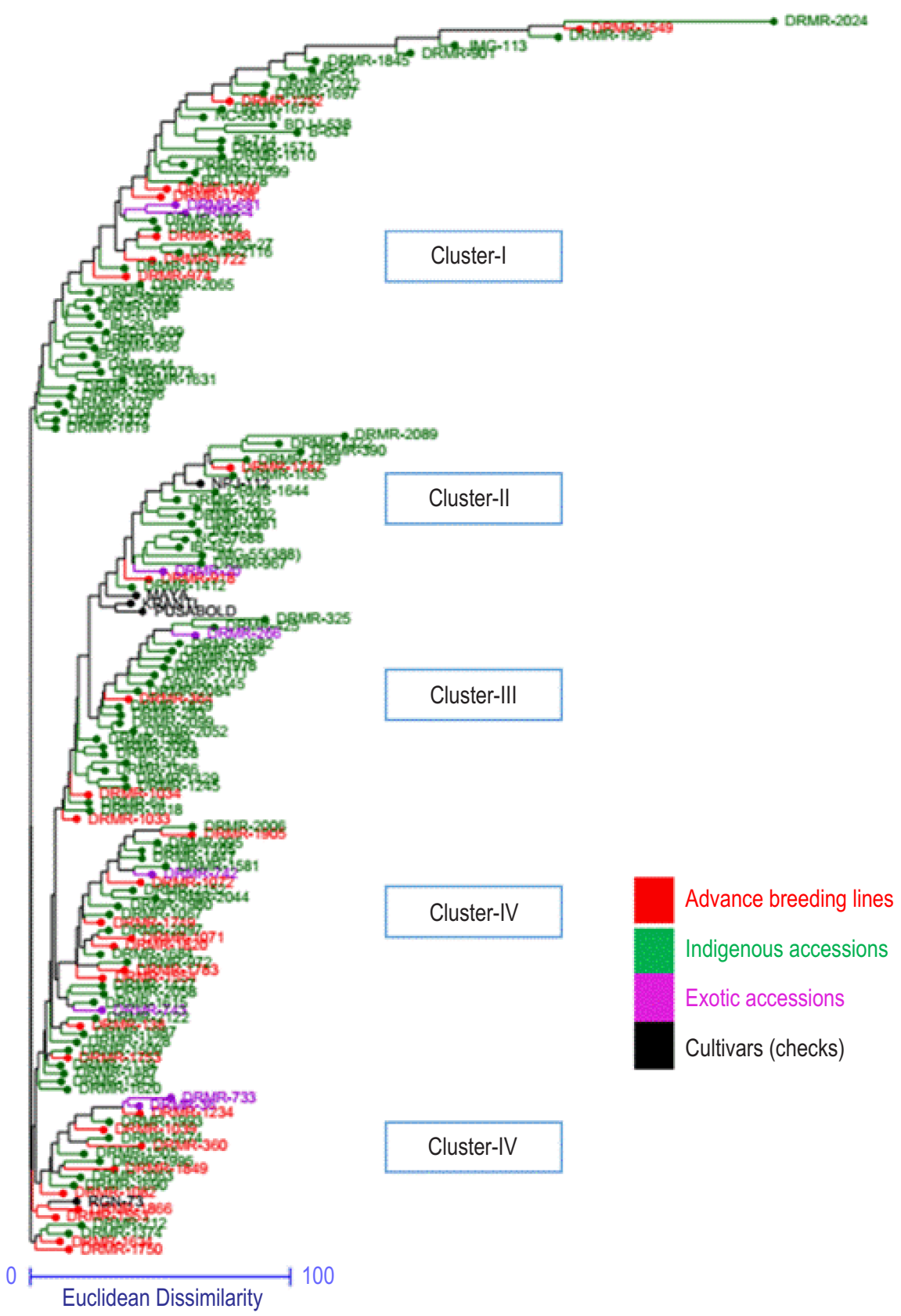

Fig.1: Neighbor joining dendrogram depicting clustering of 155 accessions of Indian mustard.

observed. Days to $50 \%$ flowering varied from 43 to 71 days with a general mean of 54 days. Not much difference was observed in genotypes for days to maturity (range: 138-146 days, mean: 142 days) which is evident from lowest PCV (1.18\%). Seed yield per plant varied from 4.14 to $40.15 \mathrm{~g}$ with a general mean of $25.19 \mathrm{~g}$. 1000-seed weight ranged from 2.05 to $7.14 \mathrm{~g}$, with a mean of $4.92 \mathrm{~g}$. Oil content varied from 36.79 to $42.57 \%$. Variability for different agro-morphological traits was estimated in terms of phenotypic coefficient of variation (PCV). A good range of variation was noticed for almost all the traits, except days to maturity and oil content. High estimate of PCV was noticed for first basal branching $(51.26 \%)$, followed by dry plant weight $(45.43 \%)$, seed yield per plant $(34.15 \%)$ and seeds/siliqua $(28.11 \%)$ whereas low estimates of PCV was observed for days to maturity (1.18\%), followed by oil content $(2.72 \%)$, initial flowering (7.02\%), Days to $50 \%$ flowering (8.88\%). Yadava et al. (2012) 
250.0

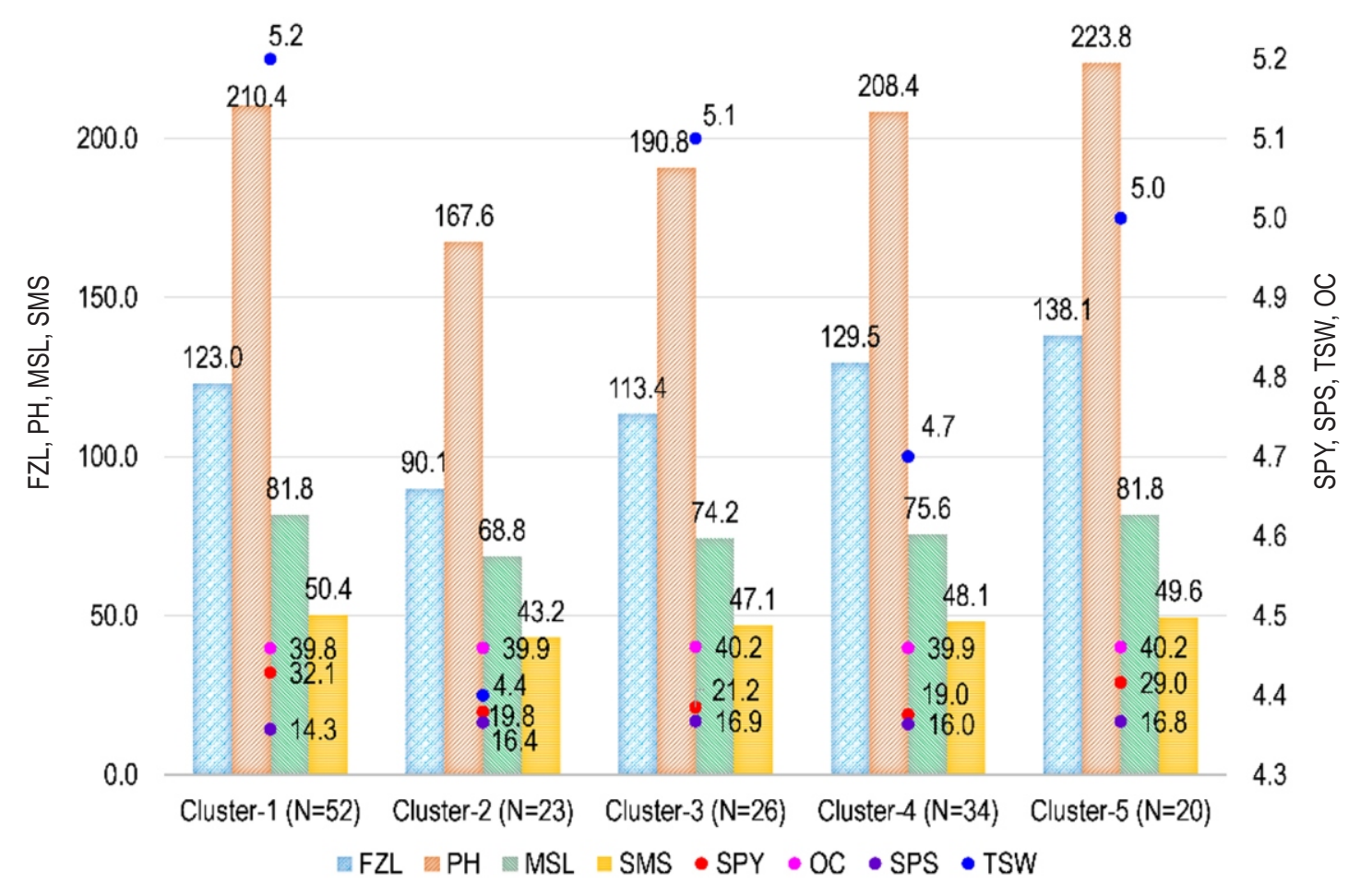

Fig. 2: Cluster means for some important traits of Indian mustard.

reported high estimates of PCV for plant height, primary branches per plant, secondary branches per plant, siliqua on main per shoot, seeds/siliqua, 1000-seed weight and seed yield per plant. They reported low variability for days to flowering, maturity and oil content. The reported high variability for yield attributing traits will help in selection of desirable genotypes of trait of interest for their further utilization in mustard breeding programme (Singh et al., 2016; Kumari etal., 2019; Lakra et al., 2020).

Improvement in seed yield can be achieved by selection using the correlated traits. Hence, Pearson's correlation coefficient was estimated to study character association between different agro-morphological traits studied and presented in Table 4. Seed yield/plant had significant and positive correlation with FZL $\left(0.192^{*}\right)$, MSL $\left(0.351^{* *}\right)$, PB $\left(0.376^{* *}\right)$, PH $\left(0.326^{* *}\right)$, SB $\left(0.451^{* *}\right)$, SL $\left(0.191^{*}\right)$, SMS $\left(0.269^{* *}\right)$, DPW $\left(0.543^{* *}\right)$, TSW $\left(0.330^{* *}\right)$. Therefore, it is indicative that indirect selection for these associated traits will be effective in selecting Indian mustard genotypes for high seed yield (Hasan et al., 2014; Ompal et al., 2018; Tiwari, 2019).

Principal Component Analysis: Principal component analysis of 16 quantitative traits is presented in Table 5. First PC had 3281.28 variance (eigen value) which was $70.79 \%$ of total variation explained indicating this axis represents majority of variations for the characters studied. It showed positive correlation with plant dry weight, plant height, seed yield, main shoot length and secondary branches. PC-II contributed $21.10 \%$ followed by PC-III (2.66\%), PC-IV (1.65\%) and PC-V (1.06\%). Cumulatively first five components explained $97.27 \%$ of the total variation in the data. Kumari and Kumari (2018) investigated principal component analyses in $31 B$. juncea genotypes, using morphological traits and reported that the first six principal components accounted for $80.92 \%$ of the diversity among the genotypes for all the traits investigated.

Identification of promising accessions: For important yield attributing traits promising accessions significantly superior over best check were identified and presented in Table 6. For plant height six accessions (DRMR-2089, DRMR-390, DRMR-1322, DRMR-1489, DRMR-1787, DRMR-1644) having significantly less $(<155 \mathrm{~cm})$ height over best check (NPJ-112; $171.2 \mathrm{~cm})$ were identified. For main shoot length $(>89 \mathrm{~cm})$ and siliqua on main shoot $(>55 \mathrm{~cm}), 14$ and 21 accessions, respectively were found significantly superior over best check (Kranti). For seeds/siliqua 09 accessions (DRMR-1849, DRMR-1620, DRMR-2065, DRMR473, DRMR-1039, DRMR-1619, DRMR-364, DRMR-1458, DRMR-304) superior over best check (RGN-73) were noticed. A total of 14 accessions (DRMR-1458, DRMR-1995, DRMR-2024, JMG-27, DRMR-1610, IB-26, DRMR-2065, JMG-113, DRMR1252, BDJ-I-164, DRMR-1427, DRMR-1588, DRMR-1596, DRMR-2055) were superior over best check (Pusa Bold) in 
terms of 1000 -seed weight $(>6.5 \mathrm{~g}$ ). Fifteen accessions (DRMR1722, BDJ-I-538, DRMR-4, JMG-113, DRMR-681, DRMR1849, DRMR-1697, DRMR-1610, DRMR-1996, DRMR-107, DRMR-1588, DRMR-1379, DRMR-1995, IB-26, DRMR-2116) recorded significantly higher seed yield per plant $(>37.0 \mathrm{~g})$. But for oil content one line DRMR 1684 was significantly superior over best check. The promising accessions identified for different traits could be used in mustard breeding programme as donors for development of transgressive segregants for important extent of economic traits (Saroj et al., 2021).

Genetic diversity analysis: Selection of parents based on the extent of genetic divergence has been successfully utilized in different crop species by different workers (Murty and Arunachalam, 1966; Sihag et al., 2004). Based on 16 quantitative traits usual Euclidean genetic distances were estimated between different genotypes of Indian mustard. Maximum distance was found between DRMR 325 and DRMR 2024 whereas minimum distance was recorded between DRMR 2052 and DRMR 2099. Dissimilarity matrix was further used for construction of $\mathrm{NJ}$ dendrogram. The NJ dendrogram (Fig.1) grouped 155 accessions (including checks) of Indian mustard into five clusters. Cluster-I was the largest and diverse cluster harbouring 52 accessions and cluster- $V$ was the smallest having 20 accessions. Cluster means for some important traits is presented in Fig.2.

Cluster-I had the highest mean for SPY $(32.1 \mathrm{~g})$ and TSW (5.2), MSL (81.8) and SMS (50.4) whereas Cluster-IV had lowest mean for SPY (19.0g). Genotypes of cluster-I can be used for yield enhancement as it showed highest cluster mean for yield and important contributing traits. Clustering of genotypes was irrespective of their geographical origins. No definite correlation between genetic and geographical diversity has been found. The present findings are in agreement with Singh et al. (2013) and Saroj et al. (2021) who studied genetic diversity in Indian mustard including indigenous and exotic line and reported no relationship between place of origin and clustering of genotypes. Similarly other workers in different crops have reported similar inferences (Sharma et al., 2016; Choudhary et al., 2017). However, these results indicate that diverse origin is not sufficient as an index of genetic diversity and this kind of genetic diversity might be due to differential selection pressure, adaptation and acclimatization and environmental settings (Das and Gupta, 1984; Sharma et al., 2013). Furthermore, Murty and Arunachalam (1966) concluded that genetic drift and selection could cause greater diversity than geographic diversity.

Advance breeding lines, indigenous and exotic accessions were distributed in all five clusters while four check cultivars namely NPJ-112, Maya, Pusa Bold and Kranti were grouped into cluster-II whereas, RGN-73 was in cluster-V. Among four checks grouped together in cluster-II, three checks (Maya, Pusa Bold, Kranti) are having one parent common (Varuna). However, grouping of four check cultivars into single cluster indicating their narrow genetic base, which is also evident from their one common parent variety Varuna. Similarly, Tudu et al. (2018) reported that clustering pattern of the genotype is highly influenced by their pedigree as compared to geographical distribution in mustard. Genotypes of different groups tend to be more distant and diverse from each other. Therefore, trait specific genotypes of different origin from different clusters can be selected for their utilization in mustard breeding programme (Devi et al., 2017; Tudu et al., 2018). However, in our study genetic diversity analysis based on morphological traits helped in identification and selection of trait specific diverse genotypes from different groups.

Since the inception of modern plant breeding only limited number of parents has been used in breeding of mustard crop due to which present day cultivars share narrow genetic base. In earlier study, less variability between present day Indian mustard cultivars was reported due to common parentage (Chauhan et al., 2011). Therefore, there is a need to infuse fresh set of diverse parents in Indian mustard breeding programme, which can be possible only through study of diverse set of germplasm for different ago-morphological traits. In this context, the present study was conducted with 155 genotypes of diverse origin in which we found broad spectrum of variability for important yield attributing traits, reported association of yield with important secondary traits and identified different trait specific diverse germplasm of Indian mustard for different yield attributing traits. Some lines were found promising for more than one traits [JMG 113 (for MSL, SMS, SPY, TSW); BDJ-I-538 (for FZL, SMS, SPY); DRMR 1849 (for FZL, SPS, SPY); DRMR-1610 (for SMS, SPY, TSW); DRMR-1995 (for FZL, SPY, TSW); DRMR-974 (for FZL, MSL, SL)]. The identified trait specific promising lines will be further revalidated in replicated trials before their further utilization in Indian mustard breeding programme.

\section{Acknowledgment}

Authors are thankful to the Director, ICAR-DRMR, Bharatpur for providing resources for conducting this experiment.

\section{Add-on Information}

Authors' contribution: H.K. Sharma: Design and conducting experiment, Data collection and analysis, Manuscript writing, editing, revisions; A. Kumar: Conducting experiment, data collection; V.V. Singh: Design of experiment, Manuscript proof reading and editing, guidance; H.S. Meena: Assistance in manuscript writing and editing; Priyamedha: Assisted in manuscript editing; P. Sharma: Assisted in manuscript editing; P.K. Rai: Manuscript editing, Overall guidance.

Research content: The research contents are original and has not been published elsewhere.

Ethical approval: Not Applicable

Conflict of interest: Authors declare no conflict of interest in the manuscript. 
Data from other sources: Not Applicable

Consent to publish: All authors agree to publish the paper in Journal of Environmental Biology.

\section{References}

Agricultural Situation in India: Agricultural Situation in India, March, 2020, Directorate of Economics and Statistics, Department of Agriculture, Cooperation and Farmers Welfare, Ministry of Agriculture and Farmers Welfare, Government of India, 64 pages (2020).

Agricultural Statistics at Glance: Agricultural statistics at glance, 2018, Government of India, Ministry of Agriculture and Farmers Welfare, Department of Agriculture, Cooperation and Farmers Welfare, Directorate of Economics and Statistics, 315 pages (2018).

Balkaya, A., R. Yanmaz, A. Apaydin and H. Kar: Morphological characterization of white head cabbage (Brassica oleracea var. capitata subvar. alba) genotypes in Turkey. New Zeal J. Crop Hort., 33, 333-341 (2005).

Chatterjee, D., S. Banga, M. Gupta, S. Bharti, P.A. Salisbury and S.S. Banga: Resynthesis of Brassica napus through hybridization between B. juncea and B. carinata. Theor. Appl. Genet., 129, 977-990 (2016).

Chauhan, J.S., K.H. Singh, V.V. Singh and S. Kumar: Hundred years of rapeseed-mustard breeding in India: Accomplishments and future strategies. Indian J. Agric. Sci., 81,1093-1109 (2011).

Choudhary, S.B., H.K. Sharma, A.A. Kumar, I. Chowdhury, R.T. Maruthi and A. Kak: Genetic diversity spectrum and marker trait association for agronomic traits in global accessions of Linumu sitatissimum L. Indus. Crops. Prod., 108, 604-615(2017).

Das, P.K. and T.D. Gupta: Multivariate analysis in blackgram (Vigna mungo). Indian J. Genet., 44, 143-247(1984).

Devi, T.R., N. Devi, Devshini, V. Yaikhom and P.R. Sharma: Genetic diversity analysis in Indian mustard [Brassica juncea (L.) Czern. \& Coss.] genotypes using agro-morphological parameters. Electr. J. Plant Breed., 8, 749-753 (2017).

Gadi, J., N.R. Chakraborty and Z. Imam: Genetic diversity analysis in Indian mustard (Brassica juncea). J. Pharmaco. Phytoche., 9, 952$955(2020)$

Gupta, A., N.C. Pant, U. Dwivedi, S. Tiwari, C.S. Pandey, R. Dhoundiyal, K.N. Maurya and O.P. Verma: Studies on correlation and path coefficient analysis for yield and yield related traits in Indian mustard [Brassica juncea (L.) Czern. \& Coss.] under timely and late sown conditions. J. Pharmaco. Phytochem., 7, 2545-2551 (2018).

Hammer, O., D.A.T. Harper and P.D. Ryan: PAST: Paleontological Statistics Software Package for Education and Data Analysis. Palaeontol. Electro., 4, 9 pages (2001).

Hasan, U., H.S.B. Mustafa, B. Tahira and T. Mahmood: Genetic variability, correlation and path analysis in advanced lines of rapeseed (Brassica napus L.) for yield components. Cercetări Agronomice Moldova, 1,157 (2014).

Hu, S., C. Yu, H. Zhao, G. Sun, S. Zhao and M. Vyvadilova: Genetic diversity of (Brassica napus L.) germplasm from China and Europe assessed by some agronomically important characters. Euphytica, 154, 9-16 (2007).

Jat, R. S., V.V. Singh, P. Sharma and P.K. Rai: Oilseed brassica in India: Demand, supply, policy perspective and future potential. Oilsee. fats, Crop. Lipid., 26, 8 (2019).

Kumari, A. and V. Kumari: Studies on genetic diversity in Indian mustard [Brassica juncea (L.) Czern. \& Coss.] for morphological characters under changed climate in the mid-hills of Himalayas. Phar. Innov. J., 7, 290-296 (2018).

Kumari, S., K. Srivastava, A. Srivastava and Akanksha: Genetic parameters and character association of yield and its attributes in Indian mustard (Brassica juncea L.). J. Oilseed Brassica, 10,140148 (2019).

Labana, K.S. and M.L. Gupta: Importance and Origin. In: Breeding Oilseed Brassicas (Eds.: K.S. Labana, S.S. Banga and S.K. Banga). Monographs on Theoretical and Applied Genetics, Vol. 19, Springer, Berlin, Heidelberg, pp. 1-7 (1993). https://doi.org/ 10.1007/978-3-662-06166-4_1

Lakra, A., G. Tantuway, A.E. Tirkey and K. Srivastava: Genetic variability and trait association studies in Indian mustard [Brassica juncea (L.) Czern. \& Coss.]. Int. J. Curr. Microbio. App. Sci., 9, 2556-2563 (2020).

Love, C.G., A.J. Robinson, G.A.C. Lim, C.J. Hopkins, J. Batley, G. Barker, G.C. Spangenberg and D. Edwards: Brassica ASTRA: An integrated database for Brassica genomic research. Nucl. Acids Res., 33, D656-D659 (2005).

Mohammadi, S.A. and B.M. Prasanna: Review and interpretation analysis of genetic diversity in crop plants-Salient statistical tools. Crop Sci., 43,1235-1248 (2003).

Murty, B.R. and V. Arunachalam: Computer programmes for some problems in biometrical genetics-l. Use of Mahalanobis $D^{2}$ in classification problems. Indian J. Genet., 27, 60-69 (1966).

Ompal, S.A. Kerkhi, P. Chand, S.K. Singh and M.K. Yadav: Study of correlation and path coefficient analysis in Indian mustard [Brassica juncea (L.) Czern. \& Coss.]. J. Pharmaco. Phytochem., 7, 890-894 (2018).

Perrier, X. and J.P. Jacquemoud-Collet: DARwin software (2006). http://darwin.cirad.fr/Darwin.

PPVFRA: Guidelines for the conduct of test for distinctness, uniformity and stability on Indian mustard [Brassica juncea (L.) Czern. \& Coss.]. and Karan rai (Brassica carinata A Braun. PPV \& FRA, Govt. of India. SG/21/2009, 30 pages (2009).

Priyanka, R. Prakash, R. Yadav, N. Kumar and A. Dhillon: Performance of different Indian mustard (Brassica juncea) varieties with saline water and graded fertilizer doses under semi-arid conditions of Haryana. J. Environ. Biol., 41,1599-1604 (2020).

Qi, X., J. Yang and M. Zhang: AFLP-based genetic diversity assessment among Chinese vegetable mustards [Brassica juncea (L.) Czern. \& Coss.]. Gene. Resou. Crop Evolu., 55, 705-711 (2008).

Rambhajan, Y.S. Chauhan and K. Kumar: Natural cross-pollination in Indian mustard. Crucif. Newsletter, 14/15, 24-25 (1991).

Rathi, A.S., D. Singh, R. Avtar and P. Kumar: Role of micronutrients in defense to white rust and Alternaria blight infecting Indian mustard. J. Environ. Biol., 36, 467-471 (2015).

Saroj, R., S.L. Soumya, S. Singh, M.S. Sankar, R. Chaudhary, Yashpal, N. Saini, S. Vasudev and D.K. Yadava: Unraveling the relationship between seed yield and yield-related traits in a diversity panel of Brassica juncea using multi-traits mixed model. Front. Plant Sci., 12,651936 (2021).

Sharma, H.K., A. Shukla, A. Kumar, A. Shukla, S.B. Choudhary and J.L. Jatothu: Variability and genetic diversity assessment in physic nut (Jatropha curcas L.). J. Medi. Plants Res., 7, 2380-2391 (2013).

Sharma, H.K., M. Sarkar, S.B. Choudhary, A.A. Kumar, R.T. Maruthi, J. Mitra and P.G. Karmakar: Diversity analysis based on agromorphological traits and microsatellite based markers in global germplasm collections of roselle (Hibiscus sabdariffa L.). Indus. Crops Produ., 89, 303-31 (2016).

Shekhawat, N., G.C. Jadeja and J. Singh: Genetic variability for yield and its components in Indian mustard [Brassica juncea (L.) Czern. \& Coss.]. Electr. J. Plant Breed., 5, 117-119 (2014). 
Sihag, R., J.S. Hooda, R.D. Vashistha and B.P.S. Malik: Genetic divergence in soybean \{Glycine max (L.) Merill.\}. Ann. Biol., 20, 1721 (2004).

Singh, B.K., A.K. Thakur and P.K. Rai: Genetic diversity and relationships in wild species of Brassica and allied genera as revealed by crosstransferable genomic STMS marker assays. Austra. J. Crop Sci., 6, 815-821 (2012).

Singh, B.K., S.B. Choudhary, S. Yadav, E.V. Malhotra, R. Rani, S. Ambawat, Priyamedha, A. Pandey, R. Kumar, S. Kumar, H.K. Sharma, D.K. Singh and P.K. Rai: Genetic structure identification and assessment of interrelationships between Brassica and allied genera using newly developed genic-SSRs of Indian Mustard (Brassica juncea L.). Indus. Crops Produ., 113, 111-120615 (2018).

Singh, K.H., R. Shakya, A.K. Thakur, D.K. Chauhan and J.S. Chauhan: Genetic diversity in Indian mustard [Brassica juncea (L.) Czernj \& Cosson] as revealed by agronomic traits and RAPD markers. Natl. Acad. Sci. Lett., 36, 419-427(2013).
Singh, R., D.P. Semwa and K.C. Bhatt: Genetic variability and diversity pattern for agro-morphological traits in Indian mustard germplasm. Ind. J. Plant Genet. Resour., 29, 52-58 (2016).

SPSS: SPSS Inc, Released. SPSS for Windows, Version 16.0. SPSS Inc, Chicago (2007).

Tiwari, V.K.: Morphological parameters in breeding for higher seed yield in Indian mustard [Brassica juncea (L.) Czern. \& Coss.]. Electr. J. Plant Bree., 10,187-195 (2019).

Tudu, V.K., A. Kumar and V. Rani: Assessment of genetic divergence in Indian mustard [Brassica juncea (L.) Czern. \& Coss.] based on yield attributing traits. J. Pharmaco. Phytoche., 7, 2093-2096 (2018).

Warwick, S.I., A. Francis and I.A. Al-Shehbaz: Brassicaceae: species checklist and database on CD-Rom. PI. Syst. Evol., 259, 249-258 (2006).

Yadava, R.K., A. Chakravarty, N. Kumar, J.R. Yadav and R. Krishna: Genetic variability and component analysis of some metric traits under sodic soil condition in Indian mustard [Brassica juncea (L.) Czern. \& Coss.]. Progres. Agricul., 12,396-401 (2012). 